\title{
Изменение физико-химических и транспортных характеристик ионообменных мембран в процессе эксплуатации при деминерализации сточных вод производства азотсодержащих минеральных удобрений
}

\author{
Козадерова О.А., Ким К.Б., Нифталиев С.И. \\ ФГБОУ ВО «Воронежский государственный университет инженерных технологий», Воронеж
}

Поступила в редакцию 13.08.2018 г.

DOI: https://doi.org/10.17308/sorpchrom.2018.18/616

Для оценки изменений, происходящих с ионообменными мембранами при их эксплуатации в промышленном электродиализном аппарате в процессе деминерализации сточных вод производства азотсодержащих минеральных удобрений, были исследованы катионо- и анионообменные мембраны Ralex CM(H)-Pes и Ralex AM(H)-Pes разного срока использования в электродиализаторе. Проведено сравнение физико-химических и структурных параметров ионообменных мембран с аналогичными характеристиками новых образцов. Определены плотность, прочность на разрыв, электропроводность, диффузионная проницаемость, потоки ионов для каждой новой и использованной мембраны при электродиализе раствора нитрата аммония.

Ключевые слова: гетерогенные ионообменные мембраны, плотность, прочность на разрыв, электропроводность, микрогетерогенная модель, электродиализ.

\section{Changes of physicochemical and transport characteristics of ion exchange membranes in the process of operation under demineralization of wastewater production of nitrogen-containing mineral fertilizers}

\author{
Kozaderova O.A., Kim K.B., Niftaliev S.I. \\ Voronezh State University of Engineering Technologies, Voronezh
}

Physicochemical and transport characteristics of heterogeneous cation-exchange (Ralex CM (H)Pes) and anion-exchange (Ralex AM (H)-Pes) membranes differing in time of using in an industrial electrodialysis vessel under desalting and concentration of waste ammonium and nitrate-containing water (conditioned membranes, membranes after one and six years of use) were investigated. The strength characteristics of the test samples were measured by the RMI-60 discontinuous machine, the density of ion-exchange membranes was determined by the pycnometric method. The estimation of the conducting properties of membranes was carried out by the contact-difference method for solutions of ammonium nitrate in the concentration range $0.01-0.3 \mathrm{~mol} / \mathrm{dm}^{3}$ at $1 \mathrm{kHz}$ frequency of an alternating current. The diffusion permeability of the investigated ion-exchange membranes was measured in a flow cell for a sodium chloride / membrane / water system. An analysis of the obtained results showed that partial destruction of the heterogeneous ion-exchange membranes is observed at their prolonged use in the electrodialysis apparatus, and such destruction leads to an increase in the diffusion permeability and electrical conductivity, however at the same time their total ex- 
change capacity decreases. In the electrodialysis of a solution of ammonium nitrate with the concentration of $0.01 \mathrm{~mol} / \mathrm{dm}^{3}$, the fluxes through the anion exchange membrane are much less than fluxes through the cation exchange membrane, since insoluble precipitation forms in the anion exchange membrane. Electrodialysis with a current density exceeding the limiting value is accompanied by irreversible dissociation of water molecules at the interface with the solution, and the ion-exchange membrane starts to be freed from precipitation, as a result of which its electrochemical regeneration takes place. The obtained results testify to insignificant deterioration of operational characteristics of ion-exchange membranes in the course of electrodialysis, which proves the prospects of its use for purification of waste nitrogen-containing water produced during the production of mineral fertilizers.

Keywords: heterogeneous ion-exchange membranes, density, tensile strength, conductivity, microheterogeneous model, electrodialysis.

\section{Введение}

При эксплуатации ионообменных мембран в электродиализном аппарате в условиях воздействия постоянного тока, повышенной температуры, изменения $\mathrm{pH}$ раствора меняются их структура и химический состав, во многом определяющие селективность и транспортные характеристики ионообменных мембран, влияющие на продолжительность их полезного применения. Срок службы современных гетерогенных мембран составляет от двух до пяти лет. Ионообменные мембраны являются главным элементом электродиализных аппаратов, их стоимость составляет 25-35\% от суммы капитальных затрат, а замена по окончании использования - вторую, после стоимости энергии, статью эксплуатационных расходов [1]. Знания о процессах старения ионообменных мембран в электродиализаторе необходимы для продления срока их полезного использования, поиска способов регенерации, а также для понимания механизма деградации мембран в зависимости от природы внешнего воздействия.

Современных исследований, касающихся старения ионообменных мембран, не так много. Изучено влияние термохимического воздействия на структуру и свойства ионообменных мембран, искусственно состаренных в лабораторных условиях [2-6], а также после эксплуатации в электродиализных аппаратах для обработки природных вод [7] и жидких сред в пищевой промышленности $[8,9]$. Исследования характеристик ионообменных мембран в растворах нитрата аммония $[10,11]$ проведены с новыми промышленными образцами, вероятно, по той причине, что электродиализ для обработки нитрат-содержащих стоков не так распространен по сравнению с традиционными методами очистки сточных вод производства минеральных удобрений (биологическая очистка, сжигание, ионный обмен) [12-16] и пока не нашел широкого применения на химических предприятиях.

Цель данной работы - сравнительный анализ физико-химических и транспортных характеристик мембран Ralex CM(H)-Pes и Ralex AM(H)-Pes, используемых в промышленном электродиализаторе в режиме концентрирования/обессоливания сточных аммоний- и нитратсодержащих вод в течение одного года и шести лет, и новых образцов таких же гетерогенных ионообменных мембран.

\section{Эксперимент}

Объектами исследования являются серийно выпускаемые $\mathrm{AO}$ «Мега» (Чехия) катионообменные и анионообменные мембраны Ralex CM(H)-Pes (RC) и Ralex $\mathrm{AM}(\mathrm{H})$-Pes (RA), применяемые при электродиализе сточных вод производства азотсодержащих минеральных удобрений. Характеристика таких сточных вод производства азотсодержащих минеральных удобрений, поступающих на обработку в электродиализатор, приведена в таблице 1 [17]. Исследуемые образцы в электродиализа- 
торе разделяли секции концентрирования/обессоливания и находились в середине аппарата. Мембраны гетерогенные, состоят из частиц ионообменной смолы (1), полиэтилена (2) и армирующей ткани (3) (рис. 1).

Таблица 1. Состав сточной воды производства азотсодержащих минеральных удобрений

\begin{tabular}{|c|c|c|c|}
\hline Концентрация & мг/дм ${ }^{3}$ & Концентрация & мг/дм ${ }^{3}$ \\
\hline $\mathrm{Ca}^{2+}$ & $0.9-6.7$ & $\mathrm{SO}_{4}^{2-}$ & $2.2-39.8$ \\
\hline $\mathrm{Mg}^{2+}$ & $0.2-3.8$ & $\mathrm{~F}^{-}$ & $3.2-92.3$ \\
\hline $\mathrm{NH}_{4}^{+}$ & $15.9-258.5$ & $\mathrm{NO}_{3}{ }^{-}$ & $15.4-312.1$ \\
\hline $\mathrm{Fe}^{2(3)+}$ & $0.01-0.17$ & $\mathrm{PO}_{4}^{3-}$ & $0.6-2.3$ \\
\hline $\mathrm{pH}$ & $4.8-8.7$ & $\mathrm{Cl}^{-}$ & $1.3-16.9$ \\
\hline
\end{tabular}

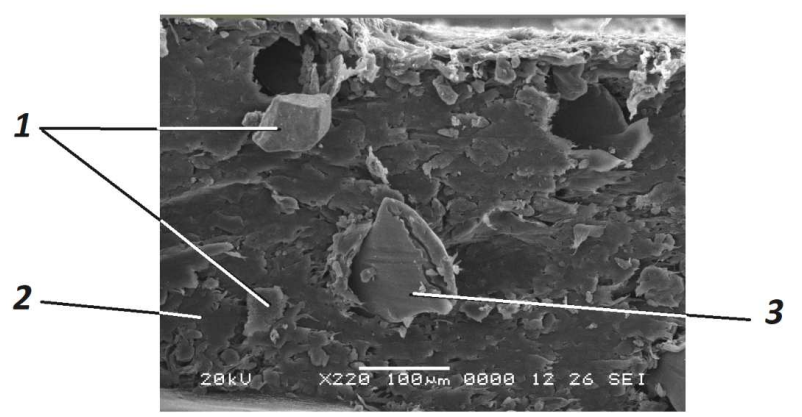

Рис. 1. Микрофотография поперечного среза гетерогенной анионообменной мембраны Ralex AM(H), полученная методом сканирующей электронной микроскопии (микроскоп модели JSM6380 LV, Япония, ЦКПНО ВГУ): 1 - частицы ионообменной смолы; 2 -полиэтилен; 3 -армирующая ткань

Основные характеристики мембран представлены в таблице 2. Исследовались новые кондиционированные мембраны (в работе обозначенные как RC0, RA0), мембраны после одного года (RC1, RA1) и шести лет (RC6, RA6) эксплуатации в промышленном электродиализном аппарате, при проведении процесса при плотностях тока, не превышающих предельные.

Таблица 2. Характеристика ионообменных мембран Ralex CM(H)-Pes и Ralex $\mathrm{AM}(\mathrm{H})-\mathrm{Pes}(\mathrm{AO} «$ Мега», Чехия)

\begin{tabular}{|c|c|c|}
\hline Показатель & Ralex CM(H)- Pes & Ralex AM(H)- Pes \\
\hline Функциональные группы & $-\mathrm{SO}_{3} \mathrm{H}$ & $-\mathrm{N}^{+}\left(\mathrm{CH}_{3}\right)_{3}$ \\
\hline Связующее & \multicolumn{2}{|c|}{ полиэтилен } \\
\hline Армирующая ткань & \multicolumn{2}{|c|}{ полиэстер } \\
\hline Полная обменная емкость, ммоль/г & $2.2 \pm 0.2$ & $1.8 \pm 0.2$ \\
\hline
\end{tabular}

Определение полной обменной емкости исследуемых ионообменных мембран проводили в статических условиях согласно ГОСТ 17552-72-1972 [18]. Для получения воспроизводимых результатов перед проведением исследований образцы кондиционировали по стандартной для данного типа мембран методике [19]. Кондиционирование заключалось в последовательной обработке мембран растворами этилового спирта, хлорида натрия, соляной кислоты (или гидроксида натрия) для перевода катионообменных мембран в $\mathrm{H}^{+}$-форму (или анионообменных - в $\mathrm{OH}^{-}$-форму). Перед проведением экспериментов мембраны отмывали в дистиллированной воде.

Прочность на разрыв $\left(\mathrm{f}_{\mathrm{p}}\right)$ и максимальное удлинение в момент разрыва $(\Delta \mathrm{l})$ для мембран определяли на разрывной машине РМИ-60 [20]. Условную прочность при растяжении рассчитывали по формуле: 


$$
f_{p}=P_{p} / S_{0},
$$

где $P_{\mathrm{p}}$ - нагрузка, соответствующая удлинению в момент разрыва, МПа; $S_{0}-$ площадь первоначального сечения образца, м².

Определение плотности ионообменных мембран проводили пикнометрическим методом [19]. Плотность ионообменной мембраны находили по формуле:

$$
\rho_{m}=\frac{\rho_{\varkappa} \cdot m}{M_{1}-\left(M_{2}-m\right)},
$$

где $\rho_{\mathrm{M}}-$ плотность ионообменной мембраны кг/м ${ }^{3} ; \rho_{ж}-$ плотность пикнометрической жидкости при $20^{\circ} \mathrm{C}$, кг $/ \mathrm{M}^{3} ; \mathrm{m}$ - навеска мембраны, г; $\mathrm{M}_{1}$ - масса пикнометра с жидкостью, г; $\mathrm{M}_{2}$ - масса пикнометра с жидкостью и навеской мембраны, г.

Для измерения электросопротивления мембран применяли контактноразностный метод [21]. Истинное сопротивление образца ионообменной мембраны находили по разности сопротивлений двух и одной мембран. В этом случае исключается влияние границ «электрод - мембрана» на величину сопротивления. Измерение электропроводности мембран проводили для растворов $\mathrm{NH}_{4} \mathrm{NO}_{3}$ в диапазоне концентраций 0,01-0,3 моль/дм³ на импедансметре RLC E7-8 при частоте переменного тока 1 кГц.

Измерения диффузионной проницаемости исследуемых ионообменных мембран $\left(\mathrm{P}_{\mathrm{M}}\right)$ проводили для системы $\mathrm{NaCl} /$ мембрана/ $\mathrm{H}_{2} \mathrm{O}$ в проточной ячейке согласно методике, подробно описанной в [22]. Расчет диффузионной проницаемости мембраны осуществляли по формуле:

$$
P_{M}=\frac{V \cdot b}{S \cdot C} \cdot \frac{d c}{d \tau}
$$

где V - объем раствора в принимающей камере, см $^{3} ; \mathrm{b}$ - толщина мембраны, см; $\mathrm{dc} / \mathrm{d} \tau$ - тангенс угла наклона зависимости «концентрация раствора в принимающей камере - время эксперимента», моль/(дм³ $\left.{ }^{3} \cdot \mathrm{c}\right) ; \mathrm{S}$ - активная площадь исследуемой мембраны, см²; C - концентрация раствора хлорида натрия в отдающей секции, моль/дм ${ }^{3}$.

Электродиализ раствора нитрата аммония с концентрацией 0,01 моль/дм ${ }^{3}$, моделирующего сточные воды производства минеральных удобрений (табл. 1), проводили в электродиализной ячейке проточного типа, представленной на рис. 2.

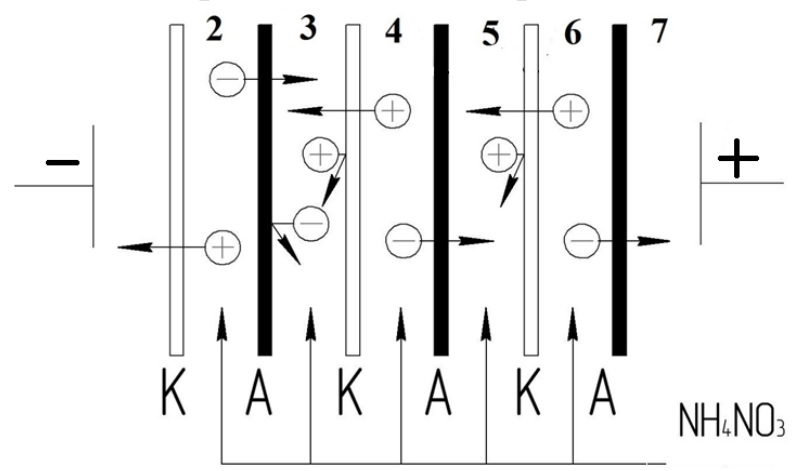

Рис. 2. Электродиализная ячейка.

К - катионообменные мембраны, А - анионообменные мембраны

Площадь рабочей поверхности мембраны составляла $14.4 \mathrm{~cm}^{2}$, скорость подачи раствора 0,46 cм/с, межмембранное расстояние $0.1 \mathrm{~cm}$. Гальваностатический режим электродиализа обеспечивался источником постоянного тока АКИП-1137-2001. При проведении эксперимента измеряли и контролировали такие параметры, как pH раствора на входе и выходе из секций обессоливания и концентрирования, сила 
тока, напряжение на мембране, а также скорость потока раствора во всех секциях. Отбор проб для определения концентрации ионов в концентрате и дилюате после достижения в электромембранной системе стационарного состояния проводили через определенные промежутки времени, время отбора пробы фиксировалось. Концентрацию ионов аммония и нитрат-ионов определяли методом прямой потенциометрии с применением ионселективных электродов $[23,24]$. Полученные значения позволили определить потоки ионов по формуле:

$$
J=\frac{\Delta C \cdot V}{S \cdot \tau},
$$

где $\Delta \mathrm{C}$ - изменение концентрации ионов в секции обессоливания (концентрирования), моль/дм ${ }^{3} ; \mathrm{V}$ - объем пробы раствора $\left(\right.$ дм $\left.^{3}\right)$, отобранный за время $\tau$ (с) из секции обессоливания (концентрирования), $\mathrm{S}$ - активная площадь мембраны, разделяющей секции, $\mathrm{cm}^{2}$.

\section{Обсуждение результатов}

На рисунке 3 представлены результаты измерения прочности на разрыв и удлинения в момент разрыва для исследуемых мембран в зависимости от срока их эксплуатации. По мере роста времени использования гетерогенных ионообменных мембран в электродиализаторе уменьшаются оба параметра. Это свидетельствует, прежде всего, о старении армирующей ткани и связующего материала - полиэтилена, которые под влиянием кислорода воздуха, света и тепла теряют свои эластические свойства и пластичность, становясь жесткими и хрупкими.
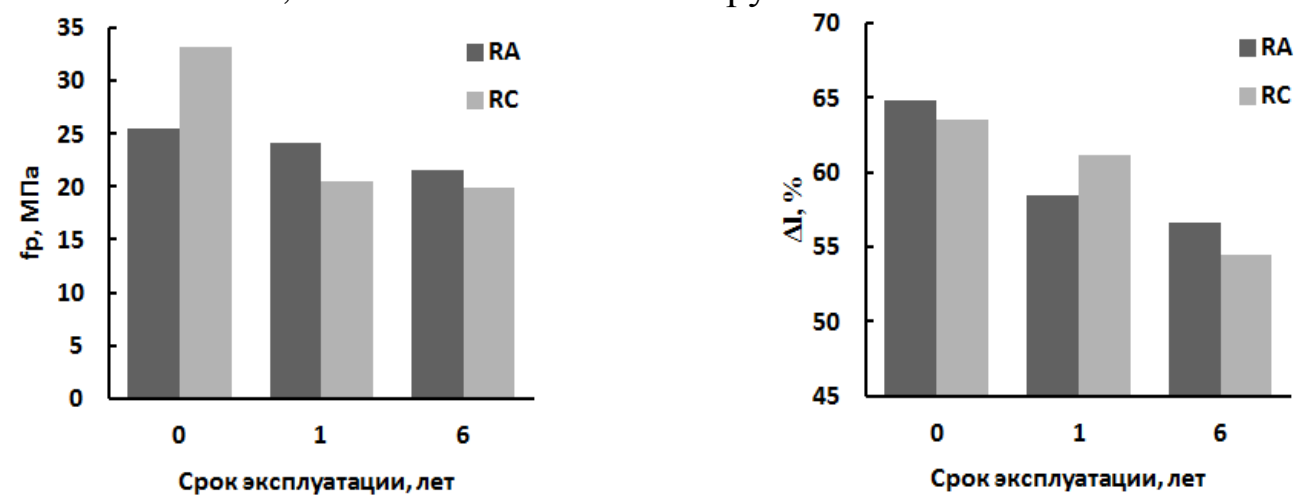

Рис. 3. Результаты изменения прочности на разрыв (слева) и удлинения в момент разрыва (справа)

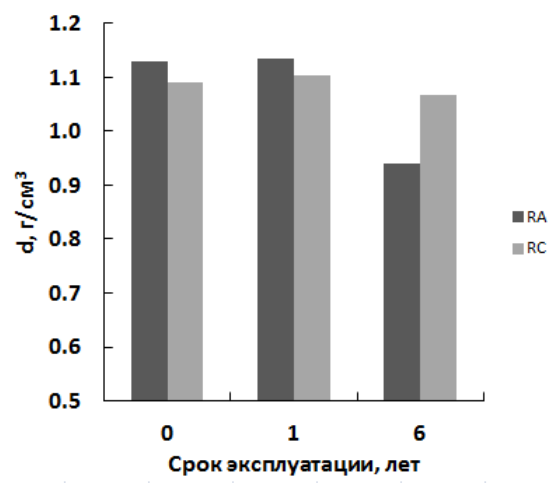

Рис. 4. Изменение плотности мембран в ходе эксплуатации

Плотность катионообменных мембран (рисунок 4), в отличие от анионообменных, за время использования в электродиализаторе практически не изменилась. 
Уменьшение плотности анионообменных образцов может быть связано с образованием дефектов в структуре мембран в ходе их эксплуатации. В работе [9] было показано, что для анионообменных мембран, применяемых в обработке жидких сред пищевых производств, плотность, наоборот, возрастает, что авторы [9] связывают с накоплением органических веществ в фазе мембраны.

Концентрационные зависимости удельной электропроводности исследуемых мембран и раствора нитрата аммония приведены на рисунке 5. Для анализа результатов использовали микрогетерогенную модель [25], согласно которой ионообменная мембрана представляется как двухфазная система и включает гелевую фазу участки заряженной матрицы с фиксированными и подвижными ионами, а также межгелевую фазу, т.е. макропоры, заполненные равновесным раствором. В рамках этой модели электропроводность мембраны $\mathrm{k}_{\mathrm{m}}$ описывается с помощью уравнения [25]:

$$
k_{m}=\overline{k^{f_{1}}} \cdot k^{f_{2}},
$$

в котором $\bar{k}$ и $f_{1}$ - электропроводность и доля гелевой фазы, $k$ и $f_{2}$ - электропроводность и доля межгелевой фазы в составе мембраны соответственно. Принимается, что параметр $k$ равен электропроводности внешнего раствора. Построение графической зависимости $\lg k_{m}-\lg k$, которая представляет собой прямую линию, позволяет по тангенсу ее наклона найти $f_{2}$. По концентрационной зависимости электропроводности мембран и раствора нитрата аммония, представленной на рисунке 5, определяли электропроводность гелевой фазы мембраны, учитывая, что в точке изоэлектропроводности $\mathrm{k}_{\mathrm{m}}=\mathrm{k}=\bar{k}^{2}$. Результаты расчета $f_{2}$ и электропроводности гелевой фазы мембраны приведены в таблице 3.

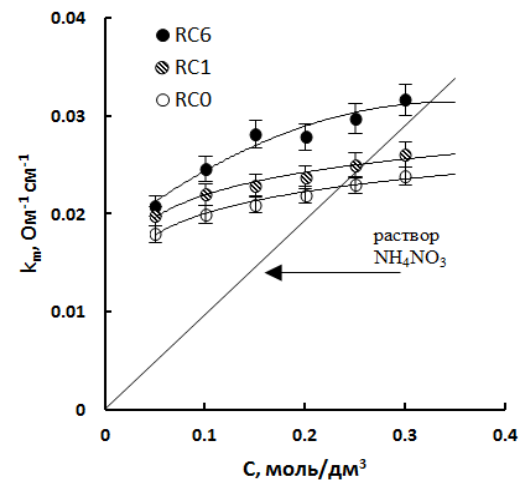

a

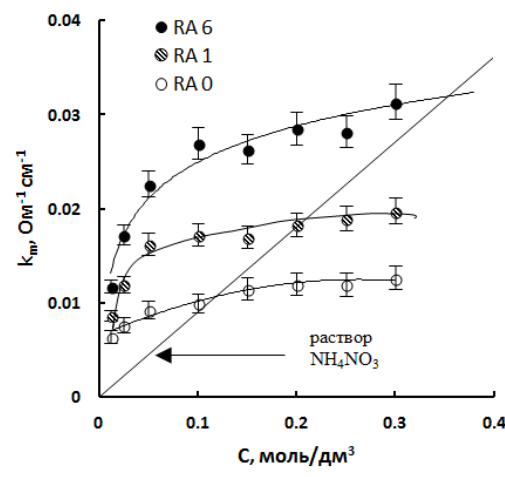

б

Рис. 5. Концентрационная зависимость удельной электропроводности мембран Ralex CM(H)-Pes (a) и Ralex $\mathrm{AM}(\mathrm{H})-\mathrm{Pes}(б)$ в растворе нитрата аммония

Эксплуатация ионообменных мембран Ralex CM(H)-Pes (a) и Ralex AM(H)Pes в течение шести лет в промышленном электродиализаторе при обработке аммоний- и нитрат- содержащих солевых растворов приводит к снижению их полной обменной емкости на 5 и $12 \%$ соответственно (табл. 3), что говорит о деструкции ионообменника. Разрушение функциональных групп и сшивающего агента ионообменных частиц в составе мембран может происходить из-за локальных изменений температуры и $\mathrm{pH}$ раствора при электродиализе. Потери обменной емкости исследуемых ионообменных мембран, определенные в данной работе, являются незначительными по сравнению с относительными изменениями емкости мембран с аналогичными функциональными группами (-71\% для катионообменных и $-84 \%$ для анионообменных образцов), эксплуатируемыми в пищевой индустрии [9]. 
Таблица 3. Характеристики ионообменных мембран

\begin{tabular}{|c|c|c|c|c|c|c|}
\hline Мембрана & $\mathrm{RC}_{0}$ & $\mathrm{RC}_{1}$ & $\mathrm{RC}_{6}$ & $\mathrm{RA}_{0}$ & $\mathrm{RA}_{1}$ & $\mathrm{RA}_{6}$ \\
\hline $\begin{array}{c}\text { Диффузионная проницаемость } \\
\left.\text { (по МаСl 0.5 моль/дм }{ }^{3}\right), 10^{-12} \mathrm{~m}^{2} / \mathrm{c}\end{array}$ & 2.1 & 2.2 & 6.4 & 0.8 & 0.8 & 6.1 \\
\hline $\begin{array}{c}\text { Полная обменная емкость } \\
\text { (по NаОН/НС), ммоль/ } / \Gamma_{\text {наб. м }}\end{array}$ & 1.14 & 1.11 & 1.08 & 1.12 & 1.04 & 0.98 \\
\hline Доля межгелевой фазы, $f_{2}$ & 0.16 & 0.15 & 0.23 & 0.21 & 0.23 & 0.27 \\
\hline $\begin{array}{c}\text { Электропроводность } \\
\text { гелевой фазы, Ом }\end{array} \mathrm{cm}^{-1}$ & 0.023 & 0.026 & 0.030 & 0.011 & 0.019 & 0.031 \\
\hline
\end{tabular}

Электропроводность мембран по мере увеличения длительности их эксплуатации в электродиализаторе растет (рис. 5). Основной причиной такого поведения ионообменников, вероятно, является рост вклада межгелевого раствора в электропроводность мембраны, что хорошо согласуется с увеличением их диффузионной проницаемости (табл. 3). Следует отметить увеличение электропроводности гелевой фазы после продолжительного использования ионообменных мембран в электродиализном аппарате, в то время как обменная емкость мембран уменьшается. Эффект антибатного изменения электропроводности гелевых участков ионообменной мембран и их обменной емкости был найден также в работах [2, 6], что авторы [2] объясняют разрушением сшивающего агента (дивинилбензола) в составе частиц ионообменника и, как следствие, увеличением степени их набухания и размеров.
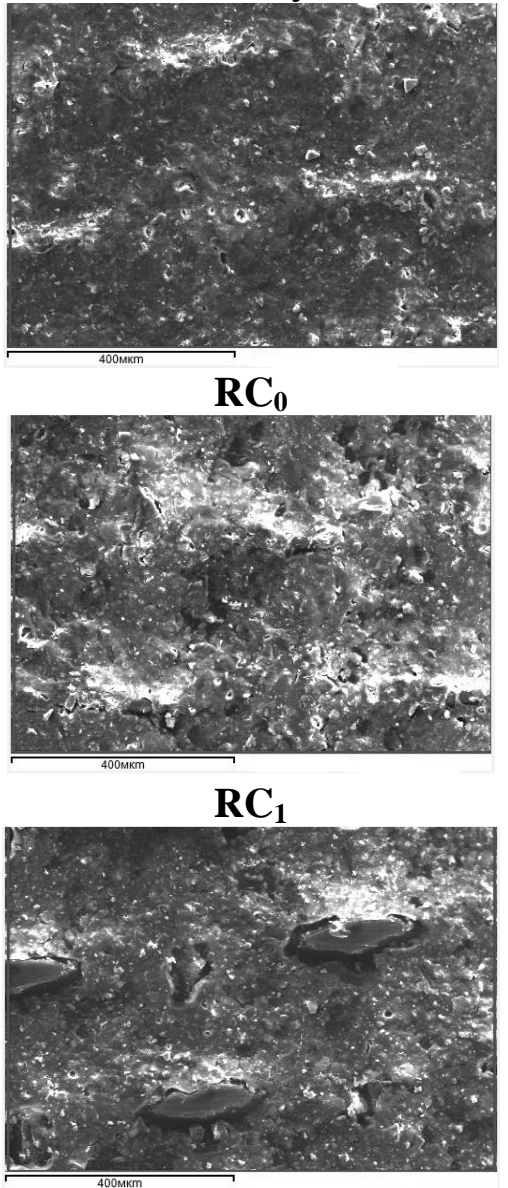

$\mathbf{R C}_{6}$

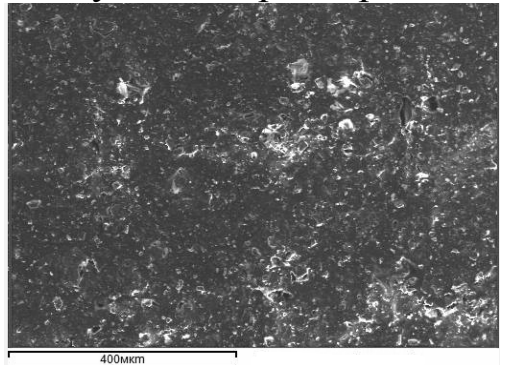

$\mathbf{R} \mathbf{A}_{0}$

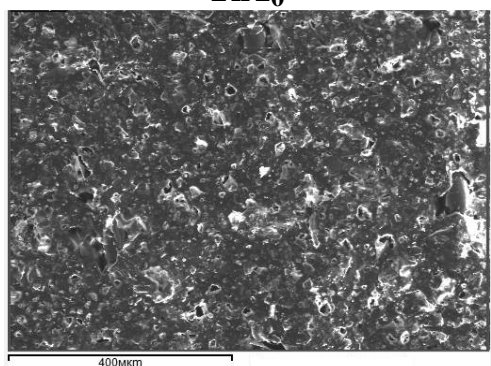

$\mathbf{R A} \mathbf{A}_{1}$

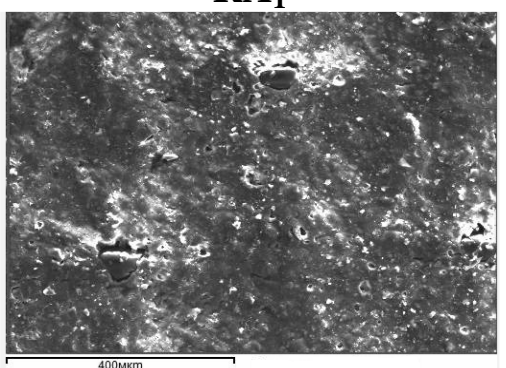

$\mathbf{R A}_{6}$

Рис. 6. Электронные микрофотографии гетерогенных мембран Ralex CM(H)-

Pes (слева) и Ralex AM(H)-Pes (справа), полученные методом сканирующей электронной микроскопии (микроскоп модели JSM6380 LV, Япония, ЦКПНО ВГУ) 
Изображения поверхности новых и использованных ионообменных мембран, полученные методом сканирующей электронной микроскопии, приведены на рисунке 6. Поверхность новых мембран Ralex $\mathrm{CM}(\mathrm{H})$-Pes и Ralex AM(H)-Pes является более гладкой и однородной. На поверхности же образцов, проработавших в электродиализном аппарате шесть лет, можно выделить заметные структурные дефекты, а также выход на поверхность армирующей ткани.

Элементный анализ поверхности мембран, проработавших длительное время в электродиализной установке, предназначенной для обессоливания сточной воды (таблица 1), показал отсутствие осадков нерастворимых солей на поверхности образцов. Вероятно, это связано с тем, что в данном случае своевременно проводилась промывка секций растворами кислоты и щелочи (это предусмотрено для любой электродиализной установки [26]), и своевременная механическая очистка мембран. Однако не исключено, что осадки могут содержаться внутри ионообменных мембран.

Электродиализ раствора нитрата аммония, проведенный для мембранных пар RC0/RA0, RC1/RA1 и RC6/RA6 показал, что потоки ионов аммония и нитрата для мембран, проработавших в течение одного года в электродиализаторе ( $\mathrm{J}_{\mathrm{RC} 1}$ и $\mathrm{J}_{\mathrm{RA1}}$ coответственно), не отличаются от потоков этих ионов через новые мембраны $\left(\mathrm{J}_{\mathrm{RC} 0}\right.$ и $\mathrm{J}_{\mathrm{RA0}}$ ) (рис. 7). Для анионообменных мембран шестилетнего срока службы найдено, что протоки нитрат-ионов $\left(\mathrm{J}_{\mathrm{RA6}}\right)$ при плотности тока не превышающей предельную $\left(\mathrm{i} / \mathrm{i}_{\mathrm{lim}}<1\right)$, заметно ниже, чем потоки этих ионов через новые образцы $\left(\mathrm{J}_{\mathrm{RA0}}\right)$ (Рисунок 6, б).

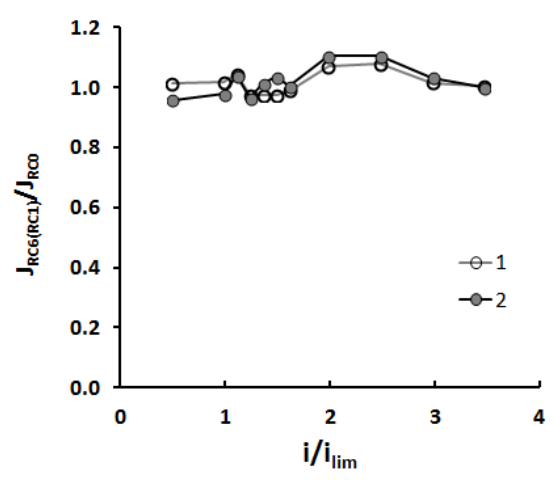

a

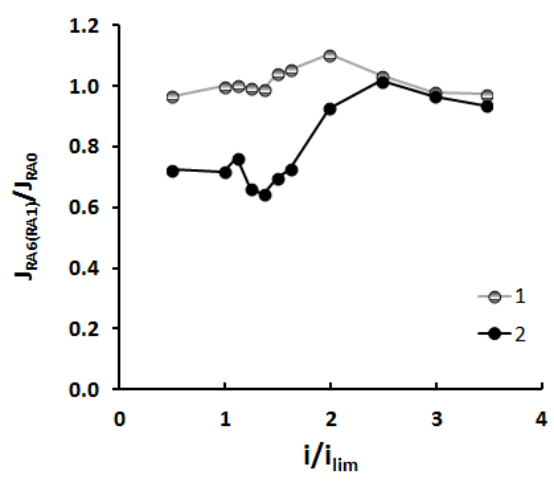

6

Рис. 7. Зависимость относительных потоков (а) - ионов аммония через катионообменные мембраны $\left(1-\mathrm{J}_{\mathrm{RC} 1} / \mathrm{J}_{\mathrm{RC} 0}, 2-\mathrm{J}_{\mathrm{RC}} / \mathrm{J}_{\mathrm{RC} 0}\right)$, (б) - нитрат-ионов через анионообменные мембраны $\left(1-\mathrm{J}_{\mathrm{RA} 1} / \mathrm{J}_{\mathrm{RA} 0}, 2-\mathrm{J}_{\mathrm{RA} 6} / \mathrm{J}_{\mathrm{RA} 0}\right)$ от безразмерной плотности тока. $\mathrm{i}$ - рабочая плотность тока, $\mathrm{i}_{\mathrm{lim}}$ - предельная плотность тока, определенная из вольтамперной характеристики ионообменной мембраны.

Кроме того, при электродиализе с мембранной парой RC6/RA6 в камере концентрирования наблюдалось подкисление растворов во всем изучаемом диапазоне плотности тока, что не характерно для мембран с такими функциональными группами. Для варианта применения новых мембран Ralex CM(H)-Pes и Ralex AM(H)-Pes (RC0/RA0), а также мембран, прослуживших в электродиализаторе в течение года (RC1/RA1), как и ожидалось, в секции концентрирования раствор подщелачивался. Вероятно, подкисление в каналах концентрирования происходит потому, что в анионообменных мембранах RA6 находятся осадки нерастворимых солей, и гидроксильные ионы, образовавшиеся при необратимой диссоциации воды на границе анионообменной мембраны и раствора в канале обессоливания (например, канал 4, рисунок 2), задерживаются в анионообменной мембране, вступая во взаимодействие с осад- 
кообразующими ионами, и в канал концентрирования (канал 5) не попадают. Следует отметить, что при $\mathrm{i} / \mathrm{i}_{\mathrm{lim}}=1.2-2.5$ в секции концентрирования наблюдается помутнение раствора: анионообменная мембрана освобождается от осадков. Таким образом, выбор оптимальных значений плотности тока и времени его воздействия позволяет проводить электрохимическую регенерацию анионообменной мембраны гидроксильными ионами, образующимися при необратимой диссоциации молекул воды на межфазной границе анионообменной мембраны и раствора канала обессоливания.

\section{Заключение}

При продолжительном использовании ионообменных мембран Ralex CM(H)Pes и Ralex AM(H)-Pes в электродиализаторе, предназначенном для обработки сточных вод производства азотсодержащих минеральных удобрений, происходит необратимое изменение их физико-механических и структурных свойств, обусловленное деструкцией армирующей ткани, инертного связующего материала (полиэтилена) и ионообменника, входящих в состав гетерогенных образцов. В результате уменьшается их полная обменная емкость, в то время как диффузионная проницаемость и электропроводность увеличиваются. Наиболее значимым изменением является накопление осадков нерастворимых солей в объеме анионообменной мембраны, это приводит к снижению потоков анионов в 1.7 раз. Однако существует возможность электрохимической регенерации анионообменной мембраны гидроксильными ионами при плотности тока, превышающей предельную. В пределах рассмотренного периода использования мембран Ralex CM(H)-Pes и Ralex AM(H)-Pes их характеристики изменяются в достаточно малой степени, что показывает перспективность применения электродиализа в химической промышленности.

\section{Список литературы}

1. Первов А.Г., Чухин В.А., Михайлин А.В. Расчет, проектирование и применение электродиализных (электромембранных) установок по деминерализации воды. М. МГСУ. 2012. $88 \mathrm{c}$.

2. Васильева В.И., Акберова Э.М., Шапошник В.А., Малыхин М.Д. // Электрохимия. 2014. T. 50. № 8. С. 875-883.

3. Васильева В.И., Письменская Н.Д., Акберова Э.М., Небавская К.А.// Журнал физической химии. 2014. Т. 88. № 8. С.1114-1120.

4. Васильева В.И., Акберова Э.М., Цхай А.А., Малыхин М.Д. «Мембраны-2013», тезисы докладов Всероссийской научной конференции (с международным участием), 1-4 октября 2013 г., Владимир, 2013, С. 348-349.

5. Sata T., Tsujimoto M., Yamaguchi T., Matsusaki K. // J. Membr. Sci. 1996. Vol. 112. pp. 161-170.

6. Dammak L., Larchet C., Grande D. // Sep. Purif. Technol. 2009. Vol. 69. pp. 43-47.

7. Яцев А.М., Акберова Э.М., Васильева В.И., Малыхин М.Д. // «Физико-химические основы ионообменных и хроматографиче- ских процессов - "ИОНИТЫ-2017", материалы XV Международной научнопрактической конференции, посвященной 115-летию открытия хроматографии и 100летию Воронежского государственного университета. 13-17 сентября 2017., Воронеж, 2017. C. 63-65.

8. Ghalloussi R., Garcia-Vasquez W., Bellakhal N., Larchet C. et al. // Separation and Purification Technology. 2011. Vol. 80/ pp. 270275.

9. Ghalloussi R., Chaabane L., Dammak L., Grande D. // Desalination and Water Treatment. 2015. Vol. 56. pp. 2561-2566.

10. Медянцева Д.Г., Шишкина С.В. // Вестник НТУ "ХПИ": Хімія, хімічна технологія та екологія. 2008. № 16. С. 80-84.

11. Niftaliev S.I., Kozaderova O.A., Kim K.B. // Journal of Electroanalytical Chemistry. 2017. Vol. 794, pp. 58-63.

12. Вайсман Я.И., Рудакова Л.В., Калинина Е.В. Патент РФ, № 2322399/ 2008.

13. Циклар-Штульц Абвассертехник ГМБХ. Патент РФ/ № 2477709/ 2013. 
14. Харлампович Г.Д., Кудряшов Р.И. Безотходные технологические процессы в химической промышленности. М. Химия. 1978. $277 \mathrm{c}$.

15. Фассбендер А.Г. Патент РФ. № 2104951. 1998

16. Тимонин А.С. Инженерноэкологический справочник: в 3 т. Калуга. Издательство Н.Бочкаревой. 2003. 2 т. 884 с.

17. ОАО «Минудобрения». Постоянный технологический регламент производства цеха НОПСВ установки очистки азотосодержащих сточных вод. Россошь. 2013, 123 c.

18. ГОСТ 17552-72-1972. Мембраны ионообменные. Методы определения полной и равновесной обменной емкости. М. Изд-во стандартов. $1972.10 \mathrm{c.}$

19. Березина Н.П., Кононенко Н.А., Дворкина Г.А. и др. Физико-химические свойства ионообменных материалов. Краснодар. Издво Кубан. гос. ун-та. 1999. 82 с.

20. ГОСТ 270-75. Резина. Метод определения упругопрочностных свойств при растя-

\section{References}

1. Pervov A.G., Chuhin V.A., Mihajlin A.V. Raschet, proektirovanie i primenenie ehlektrodializnyh (ehlektromembrannyh) ustanovok po demineralizacii vody. M. MGSU. 2012. 88 p.

2. Vasil'eva V.I., Akberova E.M., Shaposhnik V.A., Malykhin M.D., Russ. J. Electrochem., 2014, Vol. 50, No 8, pp. 789-797. DOI:10.1134/S102319351408014X

3. Vasil'eva V.I., Pismenskaya N.D., Akberova E.M., Nebavskaya K.A., Russ. J. Phys. Chem., 2014, Vol. 88, No 8, pp. 1293-1299. DOI:10.1134/ S0036024414080317

4. Vasil'eva V.I., Akberova E.M., Ckhaj A.A., Malyhin M.D., «Membrany-2013», Proceedings of the All-Russian scientific conference (with international participation), October 1-4, 2013, Vladimir, 2013, pp. 348-349.

5. Sata T., Tsujimoto M., Yamaguchi T., Matsusaki K., J. Membr. Sci., 1996, Vol. 112, pp. $\quad 161-170 . \quad$ DOI:10.1016/03767388(95)00292-8

6. Dammak L., Larchet C., Grande D., Separation and Purification Technology, 2009, Vol. 69, No 1, pp. 43-47. DOI:10.1016/j.seppur.2009.06.016

7. Yacev A.M., Akberova E.M., Vasil'eva V.I., Malyhin M.D. «Physical and chemical жении. М. ИПК Издательство стандартов. 2000. $11 \mathrm{c}$.

21. Шапошник В.А., Емельянов Д.Е., Дробышева И.В. // Коллоидный журнал. 1984. Т. 46. № 4. С. 820-822.

22. Шуткина Е.А., Невакшенова Е.Е., Письменская Н.Д., Мареев С.А., Никоненко В.В. // Конденсированные среды и межфазные гранииы. 2015. Т. 17. № 4. С. 566-578

23. $\mathrm{NH}_{4}^{+}$- селективный электрод серии «Вольта». Паспорт и руководство по эксплуатации. Санкт-Петербург. 2011. 6 с.

24. $\mathrm{NO}_{3}{ }^{-}$- селективный электрод серии «Вольта». Паспорт и руководство по эксплуатации. Санкт-Петербург. 2011. 6 с.

25. Заболоцкий В.И., Никоненко В.В. Перенос ионов в мембранах. М. Наука. 1996. $390 \mathrm{c}$.

26. РД 34.37.105-89. Главтехуправление. Методические указания по проектированию электродиализных установок для обессоливания воды на тепловых электростанциях. M. 1990. 22 c.

basis of ion-exchange and chromatographic processes - IONITS-2017», materials of the XV International Scientific and Practical Conference dedicated to the 115th anniversary of the discovery of chromatography and the 100th anniversary of the Voronezh State University, September 13-17, 2017, Voronezh, 2017, pp. 63-65.

8. Ghalloussi R., Garcia-Vasquez W., Bellakhal N., Larchet C. et al., Separation and Purification Technology, 2011, Vol. 80, pp. 270-275. DOI: 10.1016/j.seppur.2011.05.005

9. Ghalloussi R., Chaabane L., Dammak L., Grande D., Desalination and Water Treatment, 2015, Vol. 56, pp. 2561-2566. DOI: 10.1080/19443994.2014.968908

10. Medyanceva D.G., SHishkina S.V., Vestnik NTU "HPI": Himiya, himichna tekhnologiya ta ekologiya, 2008, No 16, pp. 80-84.

11. Niftaliev S.I., Kozaderova O.A., Kim K.B., Journal of Electroanalytical Chemistry, 2017, Vol. 794, pp. 58-63. http://dx.doi.org/10.1016/j.jelechem.2017.03.04 6

12. Vajsman YA.I., Rudakova L.V., Kalinina E.V. Patent RF, No 2322399, 2008. 
13. Ciklar-SHtul'c Abvassertekhnik GMBH. Patent RF, no 2477709, 2013.

14. Harlampovich G.D., Kudryashov R.I., Bezothodnye tekhnologicheskie processy $v$ himicheskoj promyshlennosti. M., Himiya, 1978, $277 \mathrm{p}$.

15. Fassbender A.G. Patent RF, No 2104951 , 1998.

16. Timonin A.S. Inzhenerno-ehkologicheskij spravochnik: $v$ 3t. Kaluga, Izdatel'stvo N.Bochkarevoj, 2003, 2t, 884 p.

17. OAO «Minudobreniya». Postoyannyj tekhnologicheskij reglament proizvodstva cekha NOPSV ustanovki ochistki azotosoderzhashchih stochnyh vod. Rossosh', 2013, 123 p.

18. GOST 17552-72-1972. Membrany ionoobmennye. Metody opredeleniya polnoj i ravnovesnoj obmennoj emkosti. M., Izd-vo standartov, 1972, $10 \mathrm{p}$.

19. Berezina N.P., Kononenko N.A., Dvorkina G.A. et al., Fiziko-himicheskie svojstva ionoobmennyh materialov, Krasnodar, Izd-vo Kuban. gos. un-ta, 1999, 82 p.

20. GOST 270-75. Rezina. Metod opredeleniya uprugoprochnostnyh svojstv pri

Козадерова Ольга Анатольевна - к.х.н., доцент кафедры неорганической химии и химической технологии Воронежского государственного университета инженерных технологий, Воронеж

Ким Ксения Борисовна - к.Х.н., старший преподаватель кафедры неорганической химии и химической технологии Воронежского государственного университета, Воронеж

Нифталиев Сабухи Ильич - д.Х.н., проф., зав. кафедры неорганической химии и химической технологии Воронежского государственного университета инженерных технологий, Воронеж rastyazhenii. Moskva, IPK Izdatel'stvo standartov, 2000, $11 \mathrm{p}$.

21. Shaposhnik V.A., Emel'yanov D.E., Drobysheva I.V., Kolloidnyj zhurnal. 1984, Vol. 46, No 4, pp. 820-822.

22. Shutkina E.A., Nevakshenova E.E., Pis'menskaya N.D., Mareev S.A. et al., Kondensirovannye sredy i mezhfaznye granicy, 2015, Vol. 17, No 4, pp. 566-578.

23. $\mathrm{NH}_{4}{ }^{+}$- selektivnyj ehlektrod serii «Vol'ta». Pasport i rukovodstvo po ehkspluatacii, SanktPeterburg, 2011, $6 \mathrm{p}$.

24. $\mathrm{NO}_{3}{ }^{-}$- selektivnyj ehlektrod serii «Vol'ta». Pasport i rukovodstvo po ehkspluatacii, Sankt-Peterburg.2011, 6 p.

25. Zabolockij V. I., Nikonenko V.V. Perenos ionov $v$ membranah. Moscow, Nauka, 1996, $390 \mathrm{p}$.

26. RD 34.37.105-89. Glavtekhupravlenie. Metodicheskie ukazaniya po proektirovaniyu ehlektrodializnyh ustanovok dlya obessolivaniya vody na teplovyh ehlektrostanciyah. M., 1990, 22 p.

Kozaderova Olga A. - Ph.D._(chemistry), associate prof., department of inorganic chemistry and chemical technology, Voronezh State University of Engineering Technology, Voronezh, kozaderovaolga@mail.ru

Kim Kseniya B. - Ph.D. (chemistry), Senior Lecturer, department of inorganic chemistry and chemical technology, Voronezh State University of Engineering Technology, Voronezh, kmkseniya@yandex.ru

Niftaliev Sabukhi I. - prof., grand Ph.D. (chemistry), head of the department of inorganic chemistry and chemical technology, Voronezh State University of Engineering Technology, Voronezh, niftaliev@gmail.com 